\title{
EL CUERPO Y SU IDENTIDAD EN LA MENTALIDAD ÁUREA ${ }^{1}$
}

\author{
María Jesús Zamora CALvo \\ Universidad Autónoma de Madrid \\ mariajesus.zamora@uam.es
}

Puella sexum mutasse

Neutrumque et utrumque

1. INTRODUCCIÓN

$\mathrm{D}$ esde la Antigüedad grecolatina hasta la llegada de la Ilustración, el Corpus hippocraticum, Aristóteles y Galeno ${ }^{2}$ fueron la base en la que se sustentaron las teorías sobre anatomía y fisiología que consideraban que existía un sexo único, donde el masculino suponía la perfección y el femenino todo lo contrario ${ }^{3}$. Sin embargo, entre estos dos extremos se admitía un continuum de formas intermedias donde se localizaban mujeres varoniles, hombres afeminados, varones menstruantes, machos que parían, mujeres peludas, etc. (Delpech 1985-1986: 548-598; Velasco 2006).

1 Este artículo se ha desarrollado dentro del proyecto «La mujer frente a la Inquisición española y novohispana» (FEM2016-78192-P), I+D de Excelencia del Ministerio de Economía y Competitividad (MINECO), financiado por la Agencia Estatal de Investigación (AEI) y el Fondo Europeo de Desarrollo Regional (FEDER, UE); y del grupo de investigación «Mentalidades mágicas y discursos antisupersticiosos (siglos XVI, XVII y XVIII)», grupo consolidado por la Universidad $\mathrm{Au}-$ tónoma de Madrid.

2 Se trata de tradiciones médicas diferentes que coinciden en este punto.

3 En 1990 Thomas Laqueur inaugura una nueva etapa en la historia cultural de la construcción de la identidad sexual al publicar Making Sex. Body and Gender from the Greeks to Freud. Partiendo de premisas teóricas foucaultianas, Laqueur sostiene que la división sexual binaria entre varón y hembra es una construcción cultural elaborada en Occidente a partir del siglo XVIII (Foucault 2005).

Edad de Oro, XXXVIII (2019), pp. 97-117, ISSN: 0212-0429 - ISSNe: 2605-3314

DOI http://doi.org/10.15366/edadoro2019.38.006 
Por ello, cuando una mujer desempeñaba trabajos de esfuerzo físico o se vestía como un hombre, entonces podía alterar su lugar dentro de esta concepción sexual única, pasando de mujer a varón. En esta época se consideraba posible transmutar de género. Era algo natural, normal, admitido dentro de la jerarquización sexual. Esto no significa que se pudiera escoger libremente uno determinado, ya que el orden que se había establecido dentro de esta sociedad estaba basado en la gradación dentro del cuerpo único. La disciplina social se ocupaba de infundir estas diferencias y de perseguir infracciones como vestirse con ropas del sexo opuesto; esto solo estaba autorizado en los carnavales y mascaradas, castigándose en el resto de casos (Dekker and Van de Pol 1989; Moreno Mengíbar y Vázquez García 2000: 91-103).

No es suficiente con tener un sexo, hay que identificarse con él, hay que producirlo como enclave de una subjetividad donde el sujeto se define, naturalmente, como el resultado de identificar el libre albedrío con el objeto «cuerpo»; con un cuerpo que, de repente, se vuelve «propio» en virtud de esta elección (Pueyo 2016: 124).

En la España áurea el género de una persona (masculino/femenino) no se establecía de acuerdo a su anatomía (varón/hembra), no se basaba en la biología, sino que tenía en cuenta una interpretación cultural más flexible y dinámica que el mero binarismo. Para Francisco Vázquez y Richard Cleminson, el sexo se identifica con un «hábito» o con un «estado»:

[...] tener uno u otro sexo era como pertenecer a un rango o estamento determinado. Cambiar de sexo era como «tomar estado», un tránsito análogo al paso de la soltería al matrimonio. Del mismo modo que se era noble o villano, se era varón o hembra; pertenecer a uno u otro orden llevaba aparejada la atribución de una serie de privilegios o prerrogativas (2018: 26-27).

En este artículo se va a abordar la hoguera de la complejidad que supone la diferenciación genérica y sexual de una persona durante el Siglo de Oro hispano. En esta época el género no era considerado algo estático ni permanente, fijado desde el mismo momento en que uno nacía. No quedaba asignado por unos órganos sexuales que marcaran y diferenciaran el macho de la hembra, el hombre de la mujer. En la mentalidad áurea se creía en la existencia de un sexo único, lo que daba lugar a una gran diversidad sexual y de género, una gradación heterogénea con una división de roles concretos desde el punto de vista social. Con ello se consiguió que el género fuera una construcción cultural y no biológica.

Por ese motivo, a lo largo de estas páginas ahondaremos en la concepción que se tenía de la identidad genérica, qué se pensaba sobre el cuerpo femenino y cómo los cambios de sexo eran admitidos con normalidad. Esbozaremos una 
clasificación de estas transexualizaciones diferenciando cuatro tipos: aquellas que tienen lugar en la pubertad, las que acontecen en la noche de bodas, las que se producen por la fuerza de la voluntad y las ocasionadas por un gran esfuerzo. Para terminar señalando la disrupción que la llegada de la Ilustración supuso al imponer el binarismo sexual y de género, cuyas consecuencias arrastramos todavía hoy en día.

\section{Sobre El CUERPo FEMENINO Y EL CAMBIO DE SEXO}

Dentro de esta gradación del sexo único, en España fue muy famoso el caso de Brígida del Río, una mujer barbuda que trabajó en la corte de los Austrias y que incluso Juan Sánchez Cotán la retrató hacia 1590. Representa, por un lado, el gusto nobiliario por lo excepcional como entretenimiento y, por otro, un claro caso de hirsutismo (Pueyo 2016: 85-89). Este crecimiento excesivo del vello, especialmente en la cara, también lo debió sufrir Magdalena Ventura, una napolitana, madre de tres hijos; a los treinta y siete años su rostro quedó cubierto por una barba espesa. Su caso atrajo la atención del mismo Felipe IV quien mandó a Ribera pintarle un cuadro (Moreno Villa 1939; Pedraza 2009; Buezo 2009; Johnston 2011).

La hagiografía cuenta, a su vez, con el caso de santa Paula Barbada, una joven hermosa que vivió en Cardeñosa (Ávila), hortelana de profesión y devota de san Segundo. Un caballero se obsesionó con ella y ante la insistencia del hombre, Paula le pidió al santo que la alejara del peligro. Y lo consiguió, ya que ante su rogativa le empezó a salir una barba poblada, tan grande que el acosador no la reconoció y cesó su hostigamiento (Cátedra 2000; Río Parra 2002: 96-97). Este caso es recogido por Nieremberg en su Cvriosa filosofia y tesoro de maravillas de la naturaleza:

Santa Paula, natural de Ávila, por librarse del furor de un caballero que desatinadamente la amaba, pidió a Dios la deformase, y al punto la [sic] salieron barbas. En semejante trance Santa Liberata o Vilgefortis, hija del rey de Portugal, impetró la misma disimulación, después fue crucificada por Cristo (1630: f. 64v).

Santa Librada o santa Wilgefortis viene a engrosar los casos de mujeres que para poner a salvo su virginidad, suplicaron una mediación divina. Le salió una barba tan tupida que le impidió casarse, aunque posteriormente muriera crucificada como mártir (Williams 1996: 311; Flor 1999: 267-305; Friesen 2001; Galé Moyano 2016).

Desde siempre, el hirsutismo femenino ha inspirado una gran atracción que queda reflejada en la literatura hispánica. Folke Gernert analiza la presencia de mujeres barbudas en el Libro de Buen Amor y la poesía cancioneril castellana 
donde «pervive el concepto de la barba como señal de lujuria en las mujeres» (2018: 261). Se las denomina «putas» y se vincula el vello corporal con la avidez por consumar cualquier deseo sexual. En la serrana de Carvajales (Gernert 2018: 262), aparte del vello corporal en la cara y las piernas, es uniceja, lleva el pelo corto y en sus pies luce unos más que evidentes juanetes, una descripción muy alejada del canon de belleza de la época. La propia Celestina es descrita así:

Días ha grandes que conozco en fin de esta vecindad una vieja barbuda que se dice Celestina, hechicera, astuta, sagaz en cuantas maldades hay. Entiendo que pasan de cinco mil virgos los que se han hecho y deshecho por su autoridad en esta ciudad. A las duras penas promoverá y provocará a lujuria si quiere (Rojas 1984: 85).

También en el resto de obras de temática celestinesca encontramos alcahuetas barbudas como en la Lozana andaluza de Francisco Delicado, donde se menciona a una «puta vieja barbuda, estrellera» (1988: 80) y a «aquella vieja cargada de cuentas y más barbas que el Cid Ruy Díaz» (1998: 121); en la Tercera parte de la tragicomedia de Celestina de Gaspar Gómez de Toledo, se la menciona de la siguiente manera: «para ejecutar la sentencia que hemos dado contra aquella barbuda» (1539: aucto XII); y en la Comedia llamada Tidea de Francisco de las Natas, se recoge: «iVoto a Dios, que viene aquí / aquella vieja barbuda!» (Pérez Priego 1993: 173, vv. 1.236-1.237), «iOh, barbuda dissantera, / mango del diablo, santona, / alcagüeta, hechizera! ¡Oh, puta vieja, jarrona!» (1993: 153, vv. 543-545) y «aquella barbuda vieja» (1993: 173, v. 1.237). Para Huarte de San Juan (Thiemann 2006: 76; Soyer 2012):

Tener mucho vello y un poco de barba es evidente señal para conocer el primer grado de frialdad y humidad. Porque, sabida la generación de los pelos y barba, todos los médicos dicen que es de calor y sequedad; y si son negros, arguye mucho calor y sequedad. La contraria temperatura se colige siendo la mujer muy lampiña, sin bozo ni vello. La que está en el segundo grado de frialdad y humidad tiene un poco de vello, pero rubio y dorado (1989: 617).

Cervantes se hace eco de esta teoría de los humores y así lo demuestra con la pastora Torralba, «que era una moza rolliza, zahareña y tiraba algo a hombruna, porque tenía unos pocos de bigotes, que parece que ahora la veo» (1989: I, 249). Debemos aquí rememorar la descripción que Sancho hace de Aldonza Lorenzo: «Bien la conozco - dijo Sancho-, y sé decir que tira tan bien una barra como el más forzudo zagal de todo el pueblo. ¡Vive el Dador, que es moza de chapa, hecha y derecha y de pelo en pecho, y que puede sacar la barba del loco a cualquier caballero!» (1989: I, 310); sin olvidar las mujeres barbudas que aparecen en $E l$ celoso extremeño: 
Entreoyeron las mozas los requiebros de la vieja, y cada una le dijo el nombre de las Pascuas; ninguna la llamó vieja que no fuese con su epitecto y adjetivo de hechicera y de barbuda, de antojadiza y de otros que por buen respecto se callan; pero lo que más risa causara a quien entonces las oyera eran las razones de Guiomar la negra, que, por ser portuguesa y no muy ladina, era extraña la gracia con que la vituperaba (1995: II, 128).

Aunque sin duda es en El coloquio de los perros donde «fuese la gente maldiciendo a la vieja, añadiendo al nombre de hechicera el de bruja, y el de barbuda sobre vieja» (1995: II, 336), indicando que, por encima de los conocimientos mágicos que tiene, se encuentra su tendencia al vicio y la lascivia (Finch 1989: 55-62).

Pero ¿cómo es considerado el cuerpo de la mujer en la mentalidad áurea? Todo parte sobre la opinión que tanto Aristóteles (1994) como luego Tomás de Aquino sostienen de la mujer. Para ellos no es más que un recipiente pasivo, un varón fallido. Creen que tiene los mismos órganos sexuales que los hombres, pero en lugar de estar colgando por fuera, se hallan ocultos por dentro (Jacquart et Thomasset 1985; Kagan and Dyer 2004; Smith 1992; Soyer 2012). Esta postura se encuentra reforzada por la teoría de los «cuatro humores», según la cual el cuerpo humano está compuesto de cuatro elementos básicos: sangre, melancolía, bilis y flema; que se corresponden con cuatro cualidades: cálido, frío, seco y húmedo; que a su vez coinciden con cuatro temperamentos: sanguíneo, melancólico, colérico y flemático; y que se localizan en cuatro órganos diferentes: corazón, bazo, hígado y cerebro (1989: 573, nota 2). Del equilibrio en cada uno de ellos depende la salud de una persona.

Para Thomas Laqueur (1990: 26-29), en los siglos XVI y XVII se considera la vagina como pene «no nacido», con lo que se sugiere que la mujer es un hombre invertido o introvertido, literalmente vertido hacia adentro. Se cree que los genitales masculinos son iguales a los femeninos. Para Mercedes Alcalá Galán, «la identidad sexual dependía exclusivamente de la calidad y el temperamento de los humores mientras que la identidad de género otorgaba el pertenecer a la esfera de lo masculino o lo femenino» (2010: 107-135). Según Huarte de San Juan:

Y de tal manera es esto verdad, que si acabando Naturaleza de fabricar un hombre perfecto, le quisiese convertir en mujer, no tenía otro trabajo más que tornarle adentro los instrumentos de generación; $\mathrm{y}$, si hecha mujer, quisiese volverla varón, con arrojarle el útero y los testículos fuera, no había más que hacer (1989: 608).

Si, tal y como mantiene Galeno (1533), todo está condicionado por el calor y la fuerza expulsiva del organismo, las transexualizaciones son posibles. Se consideraba que el pene permanecía escondido en el interior del cuerpo femenino a 
la espera de que una emisión de calor o un esfuerzo súbito propiciaran su salida al exterior:

El hombre $[\ldots]$ no difiere de la mujer sino en que tiene los genitales fuera del cuerpo. Porque, haciendo anatomía de una doncella, hallaremos que tiene dos testículos, dos vasos de simiente y la madre, con la misma compostura del miembro del hombre. Por lo cual, si en acabando naturaleza de fabricar un hombre perfecto, le quisiese convertir en mujer, no era menester más que volverle adentro los instrumentos de la generación. Y si, hecha mujer, la quisiese volver en varón, con echarle la madre y testículos fuera estaba hecho (Fragoso 1570: f. 26v).

Ya en el siglo Xvi, Blas Álvarez de Miraval considera que «la hembra es como varón manco y menoscabado» (1597: f. 286r). Bernardino de Montaña, otro anatomista destacado de la época, piensa que «la mujer es diferente del varón, y por esa razón no pudo naturaleza echar fuera del vientre los miembros de la generación como el varón el cual por la fuerza de su calor pudo echarlos fuera» (1551: f. 61v). Juan Valverde de Amusco cree que «las mujeres no menos tienen compañones que los hombres, aunque no se vean por estar metidos dentro del cuerpo, como fue necesario habiendo de concebir dentro de sí mesmas, por la cual causa fue también ordenado que todos los demás instrumentos de las mujeres necesarios a la generación estuviesen dentro del cuerpo» (1556: f. 65v). Juan Fragoso se plantea: «ipor qué los dejó escondidos naturaleza a las mujeres y patentes a los varones? Por la frialdad dellas que no los pudo pasar adelante. Pero a los hombres sí los echó afuera, como más calientes en la composición» (1570: f. 26v). Andrés de León advierte «que las mujeres también tienen testículos y miembro viril, aunque ocultos y escondidos, y redondos como los de los hombres, los cuales son un poco más largos a cada lado que el suyo» (1590: f. 28v). Fray Antonio de Fuentelapeña se une a quienes consideran que el sexo femenino es inferior al masculino, incluso al hermafrodita. Para él:

Podrán decir que a lo mejor el hermafrodita, en quien prevalece el sexo viril será más perfecto que la mujer. Lo uno porque el tal es propiamente hombre, y así capaz de ordenarse, como lo tienen Delgadillo, Vaseo y otros muchos. Lo otro, porque en tal caso puede casarse con mujer y ésta le será inferior ex illo Genesis, 2: sub viro potestate eris; lo tercero, porque el oro mezclado con la plata vale más que la plata sola; ergo etc. (2007: 247).

Pero cuando reflexiona sobre una frase de la epístola de los Efesios (4: 13) en la que se dice «quod omnes occurremus in virum perfectum $»^{4}$, estima que se trata

4 «Hasta que lleguemos todos al estado de hombre perfecto». 
de un error, ya que no hace mención al cuerpo, sino a un alma vigorosa, viril y llena de virtud, algo que puede caracterizar tanto a un hombre como a una mujer (Fuentelapeña 2007: 246). Otros autores como Francisco de Eiximenisc interpretan al pie de la letra la cita bíblica, creyendo que tanto hombres como mujeres resucitarán en el estado más perfecto de la creación. ¿Adivinan ustedes cuál es? Efectivamente, el masculino:

Es de notar que la mujer es de menos dignidad que el varón y ha movido a algunos dotores esta duda. [...] La razón que les hizo dubdar de esto que en la gloria serán los bienaventurados sin alguna fealdad personal y que parescen en la mejor figura que se pueda, y como en la especie humana la mayor perfección sea la del varón, síguese que las mugeres perderán su forma, serán restituidas a la mayor dignidad y nobleza de la especie humana, que es la de varón (Eiximenisc 1542: f. 29).

A partir de aquí se puede llegar a comprender por qué en la época áurea existe una estructura social más dúctil sobre la identidad genérica de un individuo ${ }^{5}$; una mentalidad que permite una permisibilidad a la hora de reconocer la transmutación del sexo femenino al masculino, ya que con ello desde el punto de vista doctrinal se auspicia la perfección en los humanos, pero lo que realmente se está reconociendo es la multiplicidad de los géneros. En este sentido, Huarte de San Juan afirma:

Y que se hayan vuelto mujeres en hombres después de nacidas, ya no se espanta el vulgo de oírlo; porque fuera de lo que cuentan por verdad muchos antiguos, es cosa que ha acontecido en España muy pocos años ha. Y lo que muestra la experiencia no admite disputas ni argumentos (1989: 609).

Pedro de Peramato, protomédico, opina que «hay recién nacidos que traen el sexo viril oculto al interior, y parecen hembras hasta que con la edad les sale fuera; lo cual refiere Plinio y hace pocos años ocurrió en Córdoba» (1576: f. 124r). Ambroise Paré sigue también la teoría de los humores para explicar por qué las mujeres pueden convertirse en hombres. Si el calor de las féminas se hace más intenso, es probable que cuando estas hagan un movimiento brusco, puedan expulsar los órganos sexuales que antes tenían adentro.

Y, como semejante metamorfosis tiene lugar en la Naturaleza por las razones y ejemplos alegados, por eso nunca encontramos en una historia auténtica que hombre alguno se haya convertido en mujer, ya que la Naturaleza tiende siempre a lo perfecto, y no, por el contrario, a hacer que lo que es perfecto se vuelva imperfecto (1993: 42).

5 Es más transigente mientras corresponda a los supuestos dogmáticos masculinizadores, de lo contrario es obcecada e intolerante. 
Martín del Río, en la cuestión XXII «An magicis artibus opera daemonum sexus mutari queat? ${ }^{6}$ del segundo libro de sus Disquisitionum magicarum libri $V I$, reflexiona sobre si es posible cambiar de sexo por intervención de los demonios (Zamora 2016: 125-185). Puntualiza que no se trata de una amputación de miembros, sino de una metamorfosis. Da una explicación misógina sobre la transexualización de mujer a hombre, al considerar que la naturaleza se inclina a lo más perfecto. Por ello, si a una mujer no le baja la regla, la voz se le vuelve más grave, es más hirsuta y su cuerpo más fornido, entonces para Río tan solo falta que sus órganos sexuales salgan para llegar a la perfección y reasignarse socialmente como hombre. Tras exponer estar reflexiones, Río muestra cierto escepticismo sobre estas masculinizaciones, al considerar a estas mujeres como andróginas. Incluso al final de esta cuestión reconoce que «et foeminam naturae erratum ac prolapsionem dicere, id philosopho indignum esse. Omnis si quidem rerum naturalium perfectio, ex fine petenda est: at foeminam ita formari necessarium fuit, alioqui non posset species humana conseruari ${ }^{7}$ (1612: 95).

Francesco Maria Guaccio también insiste en la imposibilidad que tienen el diablo y sus secuaces para transformar a una mujer en hombre. Cree que por medio de la brujería no se puede lograr, ya que lo único que consiguen las brujas es alterar la apariencia de los cuerpos por medio de engaños e ilusiones sobre nuestros sentidos gracias a la ayuda del Maligno (1624: 104-106). A estas voces disonantes se unieron otras como las de Francisco Hernández ${ }^{8}$, protomédico de las Indias, para quien:

[...] osaría afirmar que jamás se volvió hombre en muger, ni mujer se tornó hombre, después de una vez engendrados, cuando más después de haver nacido, porque los miembros genitales de ambos no son hábiles para se transformar de unos en otros, aunque sean, como tenemos dicho, en alguna manera semejantes, ni es obediente la materia, ni su radical complexión puede padecer la mudanza que para esto se requeriría, ni se debía imputar a naturaleza tan fea inconstancia (1966: IV, 313).

Andrés de Lorenzo en su Historia anatómica (1600: 1. 3, q. 8) está convencido de que no existen casos de cambio de sexo, más bien se tendría que hablar de personas hermafroditas que nacen con los órganos másculinos y femeninos. Es probable que durante la niñez estén ocultos y escondidos, hasta que en la

6 «¿Es posible, con artes mágicas, mudar el sexo por obra de los demonios?».

7 «Y decir que la mujer es un fracaso o mengua de la naturaleza es indigno de un filósofo. Toda perfección de las cosas naturales hay que buscarla en su finalidad. Ahora bien, fue menester que la mujer tuviese la conformación que tiene, pues de otro modo no se conservaría la especie humana».

8 Ese autor disiente de los anteriores citados que aceptan el cambio, incluso consideran que es sencillo. 
adolescencia el calor que provoca los cambios corporales los empujen hacia fuera. También puede tratarse de mujeres cuyo clítoris es más grande de lo normal, tanto que incluso se puede asimilar a un pene pequeño.

\section{HaCia una Clasificación de LOS CAMBios De SEXO}

En esta época áurea, en la que el género no queda marcado por una diferenciación anatómica, si no que se va construyendo culturalmente al considerar que no es algo inmóvil ni fijo desde el nacimiento de una persona; en un momento en el que entre machos y hembras, hombres y mujeres existe una serie de rangos en los que cada uno desempeña unos roles sociales concretos; en un tiempo en el que se tiene en cuenta la interpretación identitaria de distintas realidades, la reasignación genérica es reconocida y admitida socialmente con naturalidad y concierto. Analizando los casos de cambio de sexo en el Siglo de Oro, proponemos una clasificación basada en cuatro tipos: aquellos que tienen lugar en la pubertad, los que acontecen en la noche de bodas, los que se producen por la fuerza de la voluntad y los ocasionados por un gran esfuerzo.

\subsection{CAMBIOS DE SEXO EN LA PUBERTAD}

Durante la transición de la infancia a la vida adulta, el cuerpo de la mujer experimenta una serie de cambios que afectan a órganos y estructuras anatómicas. Por ello, en el Siglo de Oro, no se sorprendían cuando, en lugar del primer sangrado o menarquia, lo que aparecían eran los genitales masculinos, que se creía que estaban dentro, tal y como nos lo cuenta Antonio de Torquemada:

Y porque estas son cosas antiguas y no se pueda decir que alargamos los testigos, quiero que sepáis lo que cuenta el doctor Amato, médico no poco estimado en Portogal, el cual, en una obra de Medicina que hizo, dice que en un lugar que se llama Esgueria, el cual está distante de la ciudad de Coímbra nueve leguas, vivía un caballero que tenía una hija llamada María Pacheco, y que esta doncella viniendo a la edad en que le había de bajar su costumbre, en lugar della le nació (o salió de dentro, si estaba escondido) el miembro viril y ansí de hembra se convertió en varón; y le vistieron luego en hábito de hombre, mudándole el nombre y llamándole Manuel Pacheco, el cual pasó en la India Oriental y, volviendo de allá muy rico y con fama de un caballero muy estimado por su persona, se casó con una mujer principal: si tuvo hijos o no, dice que no lo supo; pero que vio que nunca le había nascido barba, sino que tenía el gesto mujeril (2012: 612).

Al leer este relato es casi inevitable sentir sorpresa, fascinación y una cierta perplejidad. El desconcierto aumenta al descubrir que el caso de María Pacheco 
fue conocido y difundido en el siglo XVII, especialmente entre médicos, filósofos, teólogos e inquisidores (Rosa Cubo y Martín Ferreira 2016: 194-211). Llama la atención la naturalidad con que se toma el suceso, como si fuera algo normal. No existe el mínimo atisbo de rechazo (López Gutiérrez 2019: 203-204). Todo lo contrario. Parece como si el cambio de sexo fuera una realidad reconocida y admitida en esta época. Otros casos de este tipo los recoge Martín del Río en su Disquisitionum magicarum libri VI:

Pontanus narrat Caietae mulierem piscatori cuidam annis quatrodecim nuptam in virum migrasse.

$[\ldots]$

Neapoli regnante Ferdinando I cum Ludovicus Guarna Salernitanus civis, quinquae filias suscepisset, quarum natum maioribus duabus alteri Franciscae, Carole alieri erat nomen, post eaquam ad quintumdecimum annum pervenerunt, ambabus genitalia membra in marium morem eruperum: mutatoque habitu, pro maribus habiti sunt, Franciscus et Carolus nuncupati.

$[\ldots]$

Auctor Antimologii scribit, sibi visum Auscis in Vasconia virum plusquam sexagenarium, canum, fortem, et hirsutum, qui ad annum decimumquintum ante puella fuerat, tandem tamen ex casu ruptis tenuibus ligamentis, pudenda erupisse, sexumque mutasse, cum ei nunquam antea menses fluxissent ${ }^{9}$ (1612: 95).

\subsection{CAMBIOS DE SEXO EN LA NOCHE DE BODAS}

La transmutación también puede ocasionarse en la noche de bodas. Plinio asegura conocer a L. Cosicio, vecino de Tisdrita, que cuando se iba a consumar su matrimonio, se masculinizó (Río 1612: 94). A Filotis de Esmirna le nació un miembro viril cuando fue a casarse por mandato de sus padres y se convirtió en varón (1612: 94). Esto también ocurrió en Laodicea, una ciudad cercana a Siria, donde Eteta, pese a transexualizarse y pasar a llamarse Eteto, siguió viviendo con su marido (1612: 94).

Item Ebuli, sub eodem Rege, Puellae, quae iam quatuor annis viro promissa sponsae nomen habuerat, qua nocte Primum viro tradita cum eo cubauit, siue ex

\footnotetext{
9 «Cuenta Joviano Pontano que en Gaeta una mujer de 14 años, prometida con un pescador, se virilizó». [...] «En Nápoles, reinando Fernando I, Ludovico Guarna, vecino de Salerno, tenía cinco hijas, de las que las dos mayores se llamaban una Francesca y la otra Carola. A las dos, al cumplir los 15 años, les brotaron órganos genitales masculinos. Cambiaron de vestidos, y la gente los tenía por varones, llamándoles Francesco y Carolo». [...] «El autor del Antimologio dice "haber visto personalmente en Huesca, en Vasconia, un hombre más que sexagenario, canoso, fuerte e hirsuto. Primero, y hasta los catorce años cumplidos, había sido niña. Hasta que casualmente se rasgaron unos tenues ligamentos, y brotándole un pene se transexuó. Por cierto, nunca anteriormente había tenido la regla"».
} 
confricatione, siue ob aliam: causam, quae ignota sit, effractis membranis, quae vt mulier videretur efficio dotem reperiuit, in virorum numero postea habita ${ }^{10}$ (Guaccio 1614: f. 109).

[Pontanus] addit idem, aliam foeminam, cum marito filium unum peperisset, subito exorta virilitate marito iam non foeminam relicto alteram duxisse, e qua liberos genuerit $^{11}$ (Río 1612: 94).

Lucinio Muciano escriuió, que él conoció a vno llamado Ariscón, que antes se dezía Arescusa, que fue muger, y se casó con vn hombre, después barbó y se mudó en varón, y se casó con otra muger (Nieremberg 1630: ff. 64v-65r).

Antoine Loqueneux, recaudador de tallas reales en Saint-Quentin, aseguró a Ambroise Paré que había visto a un hombre en la Casa del Cisne de Reims que había sido mujer hasta los catorce años:

pero hallándose jugando y retozando, acostado con una sirvienta, sus partes genitales de hombre se desarrollaron. Su padre y su madre, al reconocerlo como tal, le hicieron cambiar el nombre de Juana por el de Juan, en virtud de la autoridad de la Iglesia, y se le entregaron prendas de varón (Paré 1993: 42).

\subsection{CAMBIOS DE SEXO POR LA FUERZA DE LA VOLUNTAD}

En otros casos los cambios tenían lugar voluntariamente por acción de la fuerza imaginativa y el anhelo vehemente de convertirse en varón. En este sentido el caso más famoso lo narra Antonio de Torquemada en su Jardín de flores curiosas, al acordarse de una mujer castellana, del condado de Benavente (Zamora), que abandonó al marido porque la maltrataba, se vistió de hombre y

estando así, o que la naturaleza obrase en ella con tal pujante virtud que bastase para ello, o que la imaginación intensa de verse en el hábito de hombre tuviese tanto poder que viniese a hacer el efecto, ella se convirtió en varón, y se casó con otra mujer, lo cual no osaba descubrir ni decir como mujer de poco entendimiento; y hasta que un hombre que de antes la conocía, hallándose en el lugar de donde estaba, y viendo la semejanza que tenía con la que él le había conocido, le preguntó si por ventura era su hermano, y esta mujer, hecha varón, fiándose de él, le dijo el secreto de todo que había sucedido (Torquemada 2012: 672).

\footnotetext{
10 «En Éboli en la misma región, una muchacha había estado prometida durante cuatro años. La primera noche de su himeneo fue a la cama con su marido: pero, bien debido a la fricción o a alguna otra causa desconocida, cuando el himen que le daba apariencia de mujer fue roto, salió un órgano masculino. Entonces volvió a su casa y reclamó a los tribunales que le devolvieran su dote, y fue de allí adelante reconocida como hombre».

11 «Otra mujer — prosigue el mismo — que ya había dado un niño a su marido, se virilizó de pronto, y no siendo ya mujer se separó de su marido y se casó con otra, de la que tuvo descendencia».
} 
En otra ocasión, esta vez en la villa de Valdaracete, nació una niña llamada Estebanía, en 1496, quien desde muy joven mostró una gran habilidad en realizar actividades propiamente masculinas, como correr a gran velocidad, saltar, tirar barras, jugar a la pelota, etc., mucho mejor que cualquier hombre (Alcalá Galán 2010: 107-108; Vázquez García y Cleminson 2018: 111-119). A los veinte años fue sometida a un reconocimiento médico, se descubrió que era hermafrodita y se la dejó elegir su identidad de género. Optó por la de varón,

se casó después con otra mujer e vivieron casados y velados en facie ecclesiae. Fue hombre de mediana estatura, claro de gesto sin barba e recio de miembros. Fue maestro de esgrima con examen, tuvo escuela y arnés en Granada, y en esta villa en su arte fue tan diestro que ningún hombre jugando con él pudo ganar honra, como se pareció cuando pasó por esta villa el Rey de Francia preso por Su Magestad del Emperador Carlos quinto, que consigo traía hombres diestros y valientes, los cuales hizo esgrimir en su presencia con el dicho maestre Esteban, alias Estebanía, de los cuales batalló de todas armas, e los hirió e señaló él primeramente con la espada (Viñas y Paz 1949: I, 630-631).

Esteban se esforzó por ser el mejor en roles socialmente considerados masculinos, desenvolviéndose con valentía, fuerza y destreza, hasta llegar a casarse con la mujer que él deseó. Su tránsito es fruto de la tenacidad, la constancia y el deseo de ser reconocido, admitido y admirado como quien era, un hombre.

\subsection{CAMBIOS DE SEXO POR UN GRAN ESFUERZO}

En otras ocasiones, es un esfuerzo repentino y puntual el que desencadena la transexualización de mujer a hombre ${ }^{12}$. Esto le ocurrió a María Muñoz, mujer perteneciente a la nobleza que ingresó en un convento de Úbeda en 1605 obligada por su padre, quien no la consideraba apta para el matrimonio por sus modales varoniles, «cuando vivía en el mundo, echaba mano a una espada y disparaba un arcabuz y otras cosas que hacía de hombre» (Salamanca Ballesteros 2007: 290). Tras doce años, María experimentó una transformación en su cuerpo; mientras transportaba un saco de trigo bastante pesado, sintió un fuerte desgarro en la ingle

$\overline{12}$ Alberto Salamanca Ballesteros da una interpretación médica a estos casos: «Es fácil ver una explicación natural de estas pretendidas metamorfosis en el descenso rápido de los testículos criptorquídicos (cryptos, oculto) que por una violenta contracción de los músculos abdominales se ven obligados a franquear el conducto inguinal. En las obras de los antiguos autores que se ocupaban de monstruosidades, se atribuía tal repentino cambio por la tendencia de la naturaleza "hacia la perfección de sus obras". Cuando no se producía el descenso, la tumoración que en ocasiones provocaban los testículos incompletamente descendidos, fue tomada por algunos cirujanos por hernias inguinales (que a veces existen concomitantemente) y tratadas como tales con vendajes y bragueros» (2007: 289-290). 
saliendo de ella un pene con sus respectivos testículos. Tuvo miedo de contárselo al resto de las hermanas de la congregación porque pensaba que lo que realmente había perdido era su virginidad.

Incluso antes de la aparición del pene, la virilidad de María había llamado la atención del resto de las monjas, quienes la observaban mientras dormía, descubriendo en su cuerpo y su carácter rasgos masculinos porque «sus fuerzas y ánimo y las propiedades y sus condiciones eran de varón» (Torres [s.a.]: f. 258). Esta tensión se prolongó hasta que María confesó a fray Agustín de Torres que era «tan hombre como el que más» (Torres [s.a.]: f. 258) y que «jamás le había venido su mes y porque las monjas no le llamasen marimochacho que quando se desciplinaba hacía obstentación de la sangre en las camisas diciendo estaba con su regla» (Torres [s.a.]: f. 259). Cuando el fraile se percató de que a María le habían crecido genitales masculinos («lo vimos con los ojos y palpamos con las manos y hallamos ser hombre perfecto en la naturaleza de hombre». Torres [s.a.]: ff. 258-259) y que su tono de voz se había hecho más grave, pidió que la encerraran en una celda manteniéndola aislada del resto de la comunidad. Poco después María fue declarada varón ${ }^{13}$, ante lo cual su padre se sintió

muy contento porque es hombre rico y no tenía heredero y ahora se halla con un hijo muy hombre y que se puede casar, ella también va contenta porque después de doce años de cárcel sabe muy bien la libertad y se halla de mujer a varón que en las cosas y bienes temporales ninguna merced mayor le pudo hacer naturaleza (Torres [s.a.]: f. 259).

Un caso parecido tuvo lugar en Portugal, con Claudiana da Natividade, quien desde que ingresó en el monasterio de Santa Cruz en Portugal mostró una atração especial hacia otras profesas, aborrecía las tareas femeninas y se empeñaba en llevar bultos pesados a donde fuera necesario. La madre superiora dio la voz de alarma y Claudiana fue examinada por unas matronas, quienes consideraron que ese cuerpo tendía más hacia lo masculino que hacia lo femenino. Por ello, en 1622 fue expulsada del convento. Pero al cabo de quince años, consiguió reincorporarse y llevar una vida consagrada a «prácticas místicas» hasta sus últimos días (Aguiar 1928: 432-436).

13 Este caso gozó de un gran conocimiento y difusión en la España de los Siglos de Oro. Entre los que divulgaron la noticia se encuentra Pedro de Peramato que en su Opera medicinalia de 1576 menciona el cambio de sexo de una monja de Santo Domingo el Real con las mismas características que María Muñoz. Otro médico, Francisco Torreblanca Villalpando recuerda lo ocurrido en el mismo convento de Úbeda, pero la monja que cita se llama Magdalena Muñoz, aunque la alternancia de los nombres María y Magdalena era frecuente en esta época (Peramato 1576: f. 116; Torreblanca Villalpando 1618: f. 104). 
Por su parte, Ambroise Paré aseguró haber conocido a Germán Garnier, un joven robusto, de constitución fuerte y con una barba bastante poblada, el cual fue mujer hasta los quince años. A esa edad, mientras perseguía a unos cerdos, saltó una zanja. Justo en ese momento se le rompieron los ligamentos dejando al descubierto «los genitales y la verga viril $[\ldots]$ cosa que le ocurrió no sin dolor» (1993: 42). Tras ser revisado por médicos y cirujanos, estos determinaron que era un hombre, por lo que pasó a llamarse Germán.

En otras ocasiones, cuando se bailaba con mucho entusiasmo y enardecimiento, podían salir fuera los órganos sexuales, transmutándose de este modo en varón. Esto le sucedió a María de Vitriaco:

Passant à Vitry le François, il peut voir un homme que l'evesque de Soissons avoit nommé Germain en confirmation, lequel touts les habitants de là l'ort cogneu et veu fille iusque à l'aage vingt deux ans, nommée Marie. Il estoit à cette heure là fort barbu et vieil, et point marié. Faisant, dict il, quelque effort en saultant, ses membres virils se produisirent: et est encore en usage entre les filles de là, une chanson, par laquelle elles s'estradvertissent de ne faire point de grandes eniambées, de peur de devenir garçons, comme Marie Germain ${ }^{14}$ (Montaigne 1854: 36).

La metamorfosis podría sobrevenir tras un parto dificultoso en el que, como consecuencia del esfuerzo realizado, los genitales femeninos tomaban la posición masculina, tal y como ocurrió en Alcalá de Henares a una mujer de unos treinta años que al dar a luz «mejoró de sexo» (Nieremberg 1630: ff. 64v-65r). Pero, sin lugar a dudas, el caso más famoso y que mayor repercusión tuvo fue el de Eleno de Céspedes (AHN, Inq., leg. 234, n. ${ }^{\circ} 24$ ). Se dudaba si era hombre o mujer, lo que puso en entredicho la legalidad de su matrimonio con María del Caño. Tanto se murmuró al respecto que las autoridades de la zona decidieron investigarlo en un proceso celebrado por el tribunal del Santo Oficio de Toledo. Detuvieron a Céspedes acusándolo de sodomía, bigamia, hacerse pasar por hombre, burlarse del sacramento del matrimonio y tener pacto con el demonio. En la primera audiencia con el inculpado, este afirmó que fue bautizado como mujer en Alhama (Granada) y que nunca notó nada ajeno a su condición femenina. Incluso se casó con Cristóbal de Lombardo cuando contaba unos dieciséis años. Pero cuando parió, le salió un pequeño pene. Tomó identidad masculina. Trabajó

14 «Pasando por Vitry-le-François pude ver a un hombre al que el obispo de Soissons había nombrado Germano en la confirmación, al cual todos los habitantes del lugar habían conocido y visto como una muchacha, María de nombre, hasta la edad de veintidós años. Era en aquel entonces muy barbudo, y viejo, y no estaba casado. Según dijo, al realizar un esfuerzo para saltar, aparecieron sus miembros viriles. Y todavía es usual, entre las muchachas del lugar, una canción con la que se advierten entre ellas de no dar grandes zancadas, no vayan a convertirse en muchachos, como María Germano». 
como soldado, cirujano y sangrador. Quiso casarse con una mujer y fue entonces cuando surgió la duda sobre su naturaleza sexual, por lo que tuvo que pasar hasta tres exámenes realizados por distintos médicos. La sorpresa saltó cuando descubrieron que era una mujer con todos sus atributos. El Santo Oficio de Toledo declaró que se trataba de un fraude, acusando a Elena de Céspedes de bigamia, porque, aunque proclamó ante la audiencia que su marido había muerto, no se encontró certificado alguno que lo probara, por lo que la condena se fijó en doscientos azotes y diez años de trabajo forzado en un hospital (Vázquez García y Moreno Mengíbar 1997; Barbazza 1984: 17-40; Vollendorf 2005: 11-31; Morales Estévez 2012: 225-246).

Ya en el siglo XVIII, encontramos el episodio protagonizado por Fernanda Fernández, quien ingresó en el convento de las capuchinas de Granada (BNE ms. 12.966). Al cabo de ocho años empezó a experimentar un cambio en su fisionomía y una clara apetencia sexual hacia sus compañeras. Al principio fue tomada por loca, pero tras ser examinada, fue declarada varón. Pasó a denominarse Fernando, se vistió de hombre, aunque se dice que siempre mantuvo las habilidades adquiridas durante su vida claustral y que se entristeció al saber que nunca más volvería a regresar a dicho lugar (Vázquez García y Cleminson 2018: 163). Por esos años, en Córdoba aconteció el caso de Mariana, una monja agustina, que fue expulsada del convento al considerarla «machihembra». Luego se casó con Francisco Gómez Linares y se fue a vivir a Montilla. Cuando enviudó mostró su intención de tomar segundas nupcias, pero esta vez con su sobrina política, «haciendo papel de varón» (Muñoz Prián 2012: 189-204). Otro suceso fue recogido por el tribunal eclesiástico de Calahorra, en 1711, donde se incoó el proceso de una joven llamada Juana, que se le reasignó con el género masculino. Pasó a denominarse Juan, pero llama la atención que en esta ocasión se le prohibió terminantemente contraer matrimonio (Behrend-Martínez 2005: 1.078). Y el último caso que citamos es el de Marguerite Malaure, de apariencia «completa y delicadamente femenina», se exhibía en una barraca de feria donde mostraba, de una parte, la vulva completamente normal y unos senos perfectos y, de otra, «un miembro viril insertado internamente, falto de prepucio, pero provisto de meato urinario, con cuyo miembro podía procurarse deleites venéreos» (Von Haller 1768: 16) ${ }^{15}$.

$\overline{15}$ Se trata, según Alberto Salamanca Ballesteros (2007: 291) de un prolapso uterino, un descenso del útero. 


\section{Palabras finales}

En definitiva, durante los siglos XVI y XVIII, la identidad sexual y genérica de un individuo no se fijó a partir de la fisiología humana, no se asignó de una forma fija desde el nacimiento, con los condicionamientos que ello conllevaba. Se permitió una cierta flexibilidad basada en la concepción de sexo único, que oscilaba entre el hombre y la mujer: cuanto más se acercara la persona a lo varonil, más perfecto era, mientras que si se alejaba, se deterioraba. Con ello, se admitió una preconstrucción imaginaria-cultural que partió del ideal masculino, de ahí se fue modificando para mejorar o empeorar dependiendo de si tendía más hacia un lado u otro de la escala sexual. Se registró un número destacado de transmutaciones que fueron toleradas socialmente. Sin embargo, esta aceptación no excluyó su rareza, ya que en realidad se trataba de casos excepcionales, que despertaron una alta curiosidad por parte de los eruditos de este tiempo.

Esta mentalidad áurea en torno al género y al sexo se rompió con la llegada de la Ilustración, una época con un pensamiento tan diferente como opuesto al del Siglo de Oro. Se impuso la razón para rescatar al hombre de las tinieblas de la superstición y de la ignorancia. Triunfó una visión mecanicista de la naturaleza, a través de la que fluyó el enciclopedismo, el antropocentrismo y el laicismo. Y poco a poco se abrió camino el despotismo ilustrado, el liberalismo, junto con el universalismo. Se creyó en la bondad natural del hombre, algo que infundió optimismo y progreso a la sociedad del momento, al mismo tiempo que se empezó a considerar la diversidad sexual y de género como una patología, como una monstruosidad, que había que curar y castigar al salirse del sistema binario que hicieron hegemónico. En esto último influyó bastante el poder económico y político que comenzó a tener la burguesía, cansada de mantener y soportar a una aristocracia donde el transfuguismo de género era algo común, donde los roles masculino y femenino caminaban por una línea estrecha y, sobre todo, donde la mujer ostentaba una gran influencia y autoridad. Fue entonces cuando el sexo fijó la identidad genérica (Fausto-Sterling 2000), con lo que se logró expulsar a las mujeres de la vida pública.

Tendrán que pasar siglos para comenzar a recuperar cuotas de tolerancia, respeto y aceptación, múltiples y diversas, que sumen más que resten, en la construcción de una sociedad abierta y vital. El conocimiento del Siglo de Oro, en el que se dieron otros sistemas de identidades múltiples, debería hacernos reflexionar sobre nuestro presente, cómo está organizado y hacia dónde queremos que vaya encaminado para que todos seamos visibles y no haya nadie que reconozca con dolor: «Mis amigas tienen suerte porque quieren ser niñas y son niñas. A mí, en cambio, nadie me ve», palabras que hace tan solo un par de años Cora dijo a su madre, ya que «desde muy temprano sintió que el género y el nombre que le fueron asignados al nacer no se correspondían con su identidad». Se lo repitió 
con tanta insistencia y convicción «hasta que en casa lo entendieron e iniciaron con ella el delicado proceso de romper en plena infancia con el más primario de los esquemas sociales» (Caruso 2019). Esforcémonos para que gracias a todos lo consiga y que el oscurantismo se quede encerrado allá lejos, en el pasado.

\section{BIBLIOGRAFÍA}

Alcalá GalÁn, Mercedes (2010). «El andrógino de Franscisco de Lugo y Ávila: discurso científico y ambigüedad erótica». eHumanista, 15, pp. 107-135.

Aguiar, Asdrúbal Antonio de (1928). «Pseudo-hermafroditismo femenino (caso portugués do século XVII)». Archivo de medicina legal, 2, 4, pp. 432-436.

Álvarez de Miraval, Blas (1597). Libro intitulado la conservación de la salud del cuerpo $y$ del alma. Medina del Campo: S. del Canto.

Archivo HistóRIco Nacional (AHN - Madrid), Inq., leg. 234, n. ${ }^{\circ}$ 24. Proceso Inquisitorial de Elena o Eleno de Céspedes.

ARISTÓTELES (1994). Reproducción de los animales. Ester Sánchez Millán (trad.). Madrid: Gredos.

BARBAZzA, Marie-Catherine (1984). «Un caso de subversión social: el proceso de Elena de Céspedes (1587-1589)». Criticón, 26, pp. 17-40.

Behrend-Martínez, Edward (2005). «Manhood and the Neutered Body in Early Modern Spain». Journal of Social History, 38, pp. 1.073-1.093.

Biblioteca Nacional de España (BNE), ms. 12.966 (1).

Buezo, Catalina (2009). «La mujer barbuda en la literatura española». En Francis Desvois (ed.), Le monstre: Espagne \& Amérique Latine. Paris: L'Harmattan, pp. 161-176.

CÁtedra, María (2000). «Sobre la ambigüedad. El caso de santa Paula Barbada». En Eduardo Crespo y Carlos Soldevilla (eds.), La construcción social de la subjetividad. Madrid: Ediciones Catarata.

Cervantes, Miguel de (1989). Don Quijote de la Mancha. John Jau Allen (ed.). Madrid: Cátedra.

Cervantes, Miguel de (1995). Novelas ejemplares. Harry Sieber (ed.). Madrid: Cátedra.

CARuso, Gabo (2019). "“Yo soy Cora”, la revolución cotidiana de una niña 'trans'». El Pais Semanal, 27 de julio <https://elpais.com/elpais/2019/07/22/eps/1563791901 _093684.html> [Consultado: 27/07/2019].

DeKKer, Rudolf D. and Lotte C. VAN DE POL (1989). The Tradition of Female Transvestism in Early Modern Europe. New York: St. Martin Press.

Delicado, Francisco (1988). La Lozana Andaluza. Ángel Chiclana (ed.). Madrid: Espasa Calpe.

DeLPECH, François (1985-1986). «La patraña del Hombre Preñado: algunas versiones hispanicas». Nueva Revista de Filología Hispánica, 34.2, pp. 548-598.

EIXIMENISC, Francisco de (1542). Carro de las donas, trata de la vida y muerte del hombre christiano. Valladolid: Juan de Villaquirán. 
Fausto-Sterling, Anne (2000). Sexing the Body: Gender Politics and the Construction of Sexuality. New York: Basic Books.

FINCH, Patricia (1989). «Rojas' Celestina and Cervantes' Cañizares». Cervantes: Bulletin of the Cervantes Society of America, 93, pp. 55-62.

Flor, Fernando R. de la (1999). «La "puella pilosa". Representaciones de la alteridad femenina (de Sánchez Cotán a José de Ribera, pasando por Sebastián de Covarrubias)». En La península metafísica. Arte, literatura y pensamiento en la España de la Contrarreforma. Madrid: Biblioteca Nueva, pp. 267-305.

Foucault, Michel (2005). Historia de la sexualidad. Julia Varela y Fernando Álvarez-Uría (ed.). Madrid: Siglo XXI.

Fragoso, Juan (1570). Erotemas chirvrgicos en los qvales se enseña todo lo necessario del arte de cyrugia. Madrid: Pierres Cosin, a costa de Sebastián Yáñez.

Friesen, Ilse E. (2001). The Female Crucifix. Images of St. Wilgefortis Since the Middle Ages. Waterloo (Canada): Wilfrid Laurier University Press.

Fuentelapeña, fray Antonio de (2007). El ente dilucidado. Discurso único novísimo que muestra hay en naturaleza animales irracionales invisibles y cuales sean. Zamora: Instituto de Estudios Zamorano «Florián de Ocampo».

Galé Moyano, María José (2016). Mujeres barbudas. Cuerpos singulares. Barcelona: Bellaterra.

Galeno, Claudio (1533). Libri duo de semine. Paris: Simon Colinaeo.

GERnert, Folke (2018). Lecturas del cuerpo. Fisiognomía y literatura en la España áurea. Salamanca: Ediciones Universidad de Salamanca.

Gómez de Toledo, Gaspar (1539). Tercera parte de la tragicomedia de Celestina. Toledo: Hernando de Santa Catalina.

GuAccio, Francesco Maria (1624). Compendium maleficarum. Ex quo nefandissima in genus humanum opera venefica, ac ad illa vitanda remedia conspiciuntur. Milano: Collegio Ambrosiano.

Hernández, Francisco (1966). Obras completas. Ciudad de México: Universidad Nacional de México.

Huarte de San Juan, Juan (1989). Examen de ingenios. Guillermo Serés (ed.). Madrid: Cátedra.

JACQuart, Danielle et Claude Alexandre ThOMASSet (1985). Sexualité et savoir médical au Moyen Age. Paris: Presses Universitaires de France.

Johnston, Mark Albert (2011). Beard Fetish in Early Modern England. Farnham/Burlington: Ashgate.

KAGAN, Richard L. and Abigail Dyer (2004). Inquisitorial Inquiries: Brief Lives of Secret Jews and Other Heretics. Baltimore/London: The Johns Hopkins University Press.

Laqueur, Thomas (1990). Making Sex. Body and Gender from the Greeks to Freud. Cambridge: Harvard University Press.

LEÓN, Andrés de (1590). Libro primero de Annathomia: recopilaciones y examen general. Baeza: Juan Baptista de Montoya.

López Gutiérrez, Luciano (2019). Amor y sexo en el Siglo de Oro. Madrid: Abada Editores. 
Lorenzo, Andrés de (1600). Historia anatómica. Paris: Mettayer et Ourry.

Montaigne, Michel de (1854). Essais. Paris: F. Didot.

Montaña de Monserrate, Bernardino de (1551). Libro de la anathomia del hombre. Valladolid: S. Martínez.

Morales Estévez, Roberto (2012). «Eleno de Céspedes: el cóncavo reflejo de la historia». En María Jesús Zamora Calvo y Alberto Ortiz (eds.), Espejo de brujas. Mujeres transgresoras a través de la Historia. Madrid: Abada Editores, pp. 225-246.

Moreno Mengíbar, Andrés y Francisco Vázquez García (2000). «Hermafroditas y cambios de sexo en la España Moderna». En Antonio Lafuente y Javier Moscoso (eds), Monstruos y seres imaginarios en la Biblioteca Nacional. Madrid: Biblioteca Nacional de España, pp. 91-103.

Moreno Villa, José (1939). Locos, enanos, negros y niños palaciegos. Gente de Placer que tuvieron los Austrias en la Corte Española desde 1563 a 1700. Ciudad de México: La Casa de España en México/Editorial Presencia.

Muñoz PriÁn, Sonia (2012). «“Identidades transgenéricas” en la España del Antiguo Régimen. Un caso de cambio de sexo en la Andalucía del siglo XVIII». En Fernando Durán López (coord.), Obscenidad, vergüenza, tabú: contornos y retornos de lo reprimido entre los siglos XVIII y XIX. Cádiz: Universidad de Cádiz, pp. 189-204.

Nieremberg, Juan Eusebio (1630). Cvriosa filosofia y tesoro de maravillas de la naturale$z a$, examinadas en varias cuestiones naturales. Madrid: Imprenta del Reino.

PARÉ, Ambroise (1993). Monstruos y prodigios. Ignacio Malaxecheverría (trad.). Madrid: Siruela.

Pedraza, Pilar (2009). Venus barbuda y el eslabón perdido. Madrid: Siruela.

Peramato, Pedro de (1576). Opera medicinalia. Sanlúcar de Barrameda: Fernández Díaz.

PÉrEz PrIEGo, Miguel Ángel (ed.) (1993). Cuatro comedias celestinescas. Madrid: UNED/ Universidad de Sevilla/Universitat de València.

Plinio (1995). Historia natural. Antonio Fontán y Ana M. ${ }^{a}$ Moure (eds.). Madrid: Gredos.

PueYo, Víctor (2016). Cuerpos plegables. Anatomías de la excepción en España y en América Latina (siglos XVI-XVIII). Woodbridge (UK): Tamesis.

Río PARra, Elena del (2003). Una era de monstruos. Representaciones de lo deforme en el Siglo de Oro. Madrid/Frankfurt am Main: Iberoamericana/Vervuert.

Río, Martín del (1612). Disquisitionum magicarum libri VI. Lyon: Horacio Cardón.

RoJAs, Fernando de (1984). La Celestina. Joaquín Benito de Lucas (ed.). Barcelona: Plaza \& Janés.

Rosa Cubo, Cristina de la y Ana Isabel Martín Ferreira (2016). «La sexualidad ambigua: Un caso clínico heterodoxo en la obra de Amato Lusitano». eHumanista/Conversos, 4, pp. 194-211.

Salamanca Ballesteros, Alberto (2007). Monstruos, ostentos y hermafroditas. Granada: Universidad de Granada.

Smith, Paul Julian (1992). The Body Hispanic. Gender and Sexuality in Spanish and Spanish American Literature. Oxford: Clarendon Press. 
Soyer, François (2012). Ambiguous Gender in Early Modern Spain and Portugal: Inquisitors, Doctors, and the Transgression of Gender Norms. Leiden/Boston: Brill.

Thiemann, Susanne (2006). «Sex trouble: die bärtige Frau bei José de Ribera, Luis Vélez de Guevara und Huarte de San Juan». En Judith V. Klinger und Susanne Thiemann (eds), Geschlechtervariationem. Gender-Konzepte im Übergang zur Neuzeit. Postdam: Universitätsverlag Potsdam, pp. 47-82.

TorquemadA, Antonio de (2012). «Jardín de flores curiosas». Lemir, 16, Textos, pp. 605834.

Torreblanca Villalpando, Francisco (1618). Epithomes delictorum in quibus aperta vel occulta invocatio daemonis intervenit. Sevilla: Ildeso Rodríguez Gamarra y Francisco de Lira.

Torres, fray Agustín de [s.a.]. Cartas. Biblioteca Nacional de España (BNE), ms. 2.058.

VAlverde de Amusco, Juan (1556). Historia de la composición del cuerpo humano. Roma: J. A. De Salamanca y A. Lafrey.

Vázquez García, Francisco y Andrés Moreno Mengíbar (1997). Sexo y razón. Una genealogía de la moral sexual en España (siglos XVI y XX). Madrid: Akal.

Vázquez García, Francisco y Richard Cleminson (2018). Sexo, identidad y hermafroditas en el mundo ibérico, 1500-1800. Madrid: Cátedra.

Velasco, Sherry M. (2006). Male Delivery: Reproduction, Effeminacy, and Pregnant Men in Early Modern Spain. Nashville: Vanderbilt University Press.

VIÑas y MeY, Carmelo y Ramón Paz (1949). Relaciones histórico-geográfico-estadísticas de los pueblos de España, hechas por iniciativa de Felipe II. Madrid: Centro Superior de Investigaciones Científicas.

Vollendorf, Lisa (2005). The Lives of Women. A New History of Inquisitional Spain. Nashville: Vanderbilt University Press.

Von Haller, Albrecht (1768). Operum Anatomici Argumenti Minorum. Lausannae: Francisci Grasset \& Socior.

Williams, David (1996). Deformed Discourse. The Function of the Monster in Medieval Thought and Literature. Exeter: University of Exeter.

Zamora Calvo, María Jesús (2016). Artes maleficorum. Brujas, magos y demonios en el Siglo de Oro. Barcelona: Calambur Editorial.

Recibido: 10/08/2019

Aceptado: 14/09/2019 


\section{EL CUERPO Y SU IDENTIDAD EN LA MENTALIDAD ÁUREA}

Resumen: La mentalidad áurea creía en la existencia de un sexo único, lo que daba lugar a una gran diversidad sexual y de género, una gradación muy heterogénea que iba desde la perfección masculina a la imperfección femenina, con una división de roles concretos desde el punto de vista social. Por ello, en este artículo ahondaremos en la concepción que se tenía de la identidad de género, qué se pensaba sobre el cuerpo femenino, cómo los cambios de sexo eran admitidos con normalidad, y esbozaremos una clasificación de estas transexualizaciones diferenciando cuatro tipos. Terminaremos señalando la disrupción que la llegada de la Ilustración supone al imponer el binarismo sexual y de género, cuyas consecuencias arrastramos hoy en día.

Palabras Clave: identidad de género, cuerpo femenino, cambios de sexo, Siglo de Oro español

\section{The Body and its Identity in the SPANISH Golden Age Mentality}

Aвstract: The Spanish Golden Age mentality believed in the existence of one sex only, which gave rise to a great sexual and gender diversity, a quite heterogeneous gradation that went from the male perfection to the female imperfection, with a specific division of roles from a social point of view. Therefore, in this article we will delve into the conception of gender identity, to what consideration the female body was held, how sex changes were admitted with normality, and we will outline a classification of these transexualizations differentiating four types. In conclusion, noting the disruption that the arrival of the Enlightenment assumes by imposing sexual and gender binarism, whose consequences we still drag to this day.

KeYwords: gender identity, female body, sex changes, Spanish Golden Age 